\title{
ChemComm
}

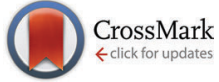

Cite this: Chem. Commun., 2014 50, 12177

Received 1st July 2014, Accepted 13th August 2014

DOI: $10.1039 / c 4 c c 05007 j$

www.rsc.org/chemcomm

\section{Stepwise radial complexation from the outer layer to the inner layer of a dendritic ligand: a phenylazomethine dendrimer with an inverted coordination sequence $\dagger$}

\author{
Ken Albrecht, Noriko Sakane and Kimihisa Yamamoto*
}

\begin{abstract}
A para-substituted phenylazomethine dendrimer (pGnA) coordinates to Lewis acids in a stepwise radial fashion from the inner layer to the outer layer. The inversion of this coordination sequence was achieved for the first time by just changing the substitution position of the phenylazomethine group from the para position to the meta position ( $\mathrm{mGnA}$ ).
\end{abstract}

The energy (potential) level distribution in a molecule or a molecular system is an important factor that controls the electrical properties. Especially, some of the geometric potential architectures such as gradients (steps), square well potentials, and $\mathrm{p}-\mathrm{n}$ junctions are the essence of the photosynthesis system, ${ }^{1}$ and some electronic devices, such as laser diodes, ${ }^{2}$ light emitting diodes, ${ }^{3}$ and solar cells. ${ }^{4}$ Therefore, the manipulation of the intra- and inter-molecular potential structure is a promising key technology for next generation materials that are related to electronics and photonics.

Dendrimers ${ }^{5}$ are molecules with few $\mathrm{nm}$ to $10 \mathrm{~nm}$ dimensions that have a perfectly branched molecular backbone. Due to the distinctive spherical molecular structure and stable conformation, dendrimers have the ability to locate functional groups in a threedimensional space. This feature is appropriate to build up spherical potential gradients, such as in light harvesting systems with several chromophores, ${ }^{6}$ and redox cascades. ${ }^{7}$ The para-substituted phenylazomethine dendrimer (pDPA, Fig. 1$)^{8}$ is reported to have an innerlayer electron rich and an outer-layer electron poor potential gradient even while its backbone is formed by the repetition of absolutely identical monomers. ${ }^{9}$ This spontaneous expression of the potential gradient was an unexpected achievement and is not an extension of the usual method to construct a potential gradient (connecting different molecules). According to this anomalous feature, DPAs has a layer-by-layer gradient of basicity and can coordinate to Lewis acids in a stepwise radial fashion. ${ }^{8}$ This can be used to locate the precise number of Lewis acids, making it useful as a sub-nanometer

Chemical Resources Laboratory, Tokyo Institute of Technology,

4259 Nagatsuta Midori-ku Yokohama 226-8503, Japan.

E-mail: yamamoto@res.titech.ac.jp; Fax: +81-45-924-5259

$\dagger$ Electronic supplementary information (ESI) available: Experimental section, identification data, calculated molecular models, titration results, cyclic voltammograms, and NMR spectra. See DOI: 10.1039/c4cc05007j
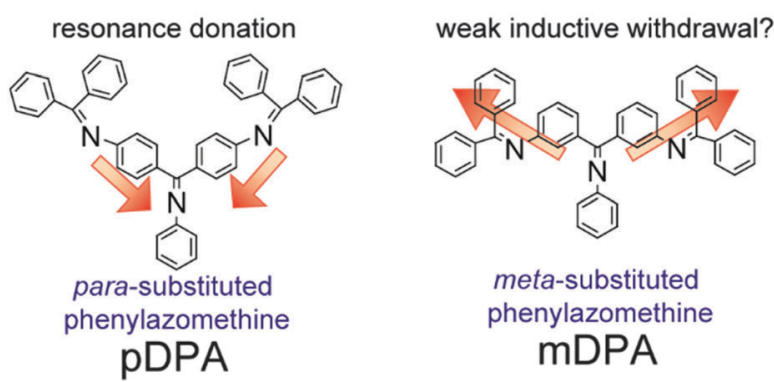

meta-substituted phenylazomethine mDPA
Fig. 1 Image of the different substituent effects that lead to an inverted potential gradient in para- and meta-substituted phenylazomethine dendrimers (DPAs)

metal cluster template. ${ }^{10}$ It can further be used as a molecular rectifier for electron transfer, ${ }^{11}$ and is expected to be a model for "atom mimicry". ${ }^{12}$ The expression mechanism of the potential gradient is still unclear, but the importance of the rigid $\pi$-conjugated backbone and the electron donation from the outer layer to the inner layer has been pointed out. ${ }^{13}$ Recently, we have tried to control the coordination sequence by installation of an electron withdrawing group in the core. ${ }^{14}$ However, this approach only weakened the binding of the innermost layer, and inversion of the potential gradient was not achieved. As mentioned above, the electron donation (substituent effect) from the outer layer to the inner layer of phenylazomethine seems to play an important role in the spontaneous expression of the inner-layer electron rich potential gradient. The origin of this donation is ascribable to resonance donation. Therefore, presumably, changing the substitution position from para to meta will suppress this donation and allow a weak inductive electron withdrawal due to the difference in the electron negativity of the carbon and nitrogen atoms (essentially this should also exist in the para substituted DPA, but the withdrawal is masked with the stronger donation). Accordingly, herein we report the synthesis and an inverted potential gradient (coordination sequence) of the meta-substituted phenylazomethine dendrimer (mDPA) together with the expression mechanism.

The synthesis of the meta-substituted phenylazomethine dendron is summarized in Scheme S1 (ESI $\dagger$ ). The traditional 


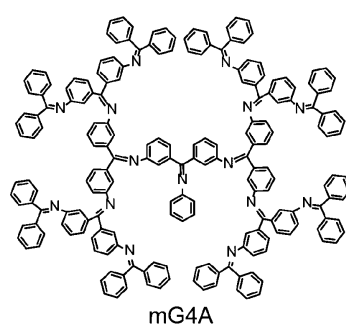

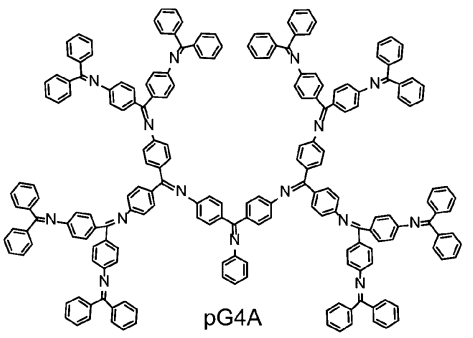<smiles>CC(C)ON1C=CCC1</smiles>

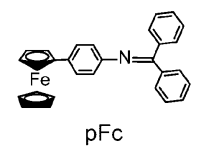

Fig. 2 Structure of fourth-generation meta-, and para-substituted phenylazomethine dendrimers, and phenylazomethine substituted ferrocenes.

para-substituted phenylazomethine dendrimer (PDPA) is synthesized by a convergent method that repeats the dehydration reaction and oxidation of the benzyl position to reproduce the ketone. ${ }^{15}$ The $\mathbf{m D P A}$ dendrons were also synthesized according to this method. To measure the basic property and the existence of the potential gradient, the G1 to G4 dendrons were reacted with aniline to give a 1-substituted dendrimer ( $\mathbf{m G n A}(n=$ generation), Fig. 2, Scheme S2, ESI $\uparrow$ ). Additionally, meta- and para-phenylazomethine substituted phenyl ferrocenes were synthesized (pFc, and $\mathbf{m F c}$, Fig. 2, Scheme S3, ESI $\dagger$ ) by reacting ferrocene-linked anilines ${ }^{16}$ with benzophenone. All the new compounds were identified by ${ }^{1} \mathrm{H}$ NMR, ${ }^{13} \mathrm{C}$ NMR, MALDI-TOF MS, and elemental analysis. Additionally, the purity of $\mathbf{m G n A}$ was checked by HPLC analysis (see ESI $\dagger$ ).

To compare the conjugation length of $\mathbf{m G n A}$ and $\mathbf{p G n A}$, the UV-vis absorption spectra were measured (Fig. S24, ESI†). The peak of $\mathbf{P G n A}$ at around $350 \mathrm{~nm}$ showed a bathochromic shift when the generation increased from pG2A to pG4A $(342,360$, and $367 \mathrm{~nm}$, respectively). On the other hand, the absorption peaks of mG2A, mG3A, and mG4A were consistent (326, 325, and $324 \mathrm{~nm}$, respectively). The absorption edge also showed the same trend. These results suggested that the conjugation-induced inner-layer electron rich potential gradient of PDPA is suppressed in mDPA.

The steric crowding around the binding site may affect the binding properties. Therefore, to obtain steric information about PDPA and MDPA, the intrinsic viscosity was measured and a Mark-Houwink-Sakurada plot was created (Fig. S25, $\mathrm{ESI} \dagger$ ). The intrinsic viscosity of mDPA was slightly lower than that of PDPA and the hydrodynamic radius also decreased. This could also be confirmed by the molecular model (Fig. S26, ESI $\dagger) .{ }^{17}$ However, the difference in size and steric hindrance around the binding sites is small, thus it can be assumed that the steric factor does not affect the complexation.

The stepwise complexation of DPAs can be observed by careful UV-vis titration with Lewis acids. In the case of pG4A, four isosbestic points can be observed during the titration, and the shift occurs when the amount of Lewis acids matches the number of imine sites in each layer of pG4A from the inner layer $(1,2,4$, and 8 equivalents). One isosbestic point corresponds to one equilibrium state, therefore, this strongly supports the plausible assumption

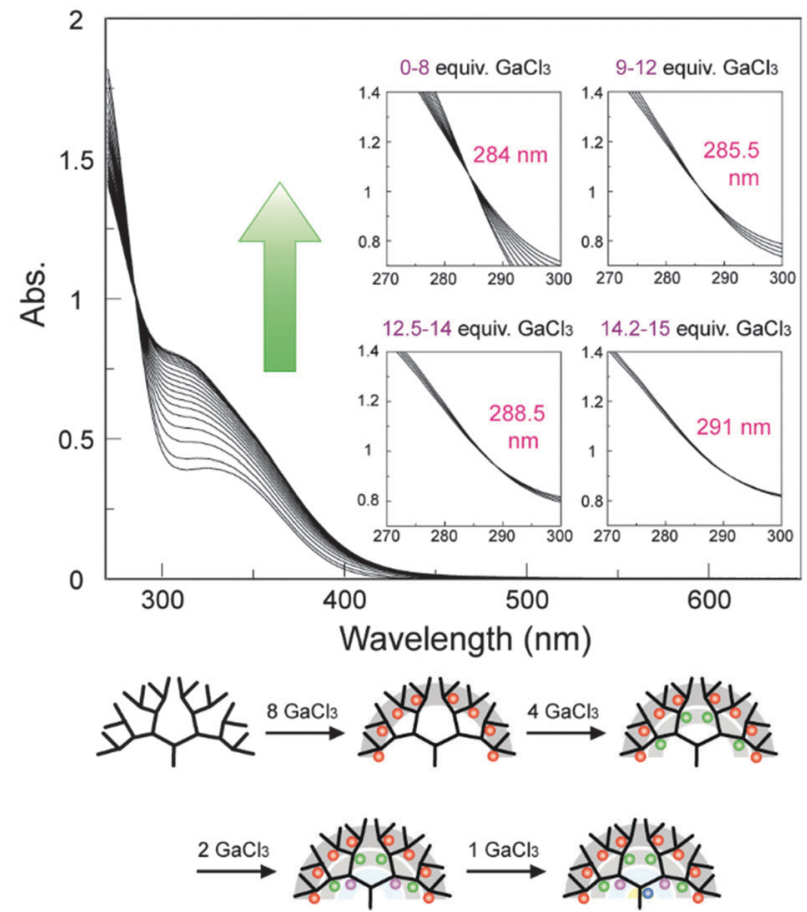

Fig. 3 UV-vis spectra of $\mathbf{m G} 4 \mathrm{~A}$ during the addition of $\mathrm{GaCl}_{3}$ (solvent is chloroform: acetonitrile $=1: 1$ ) and the image of the stepwise radial complexation from the outer layer to the inner layer of the dendrimer.

that the complexation of $\mathbf{P G 4 A}$ is occurring sequentially from the inner layer to the outer layer. Following this method, the UV-vis titration of mG4A with $\mathrm{GaCl}_{3}$ in chloroform: acetonitrile $=1: 1$ solvent was performed (Fig. 3 and Fig. S27, $\mathrm{ESI} \dagger)\left(\mathrm{GaCl}_{3}\right.$ was chosen because it complexes strongly with imines ${ }^{18}$ and does not have any absorption beyond $270 \mathrm{~nm}$ ). During the titration, four isosbestic points were observed, and the amount of $\mathrm{GaCl}_{3}$, which was necessary for the shift, was $8,4,2$, and 1 equivalents. This corresponds to the number of imine sites from the outer layer of mG4A and indicates the sequential complexation from the outer layer to the inner layer. Other generations ( $\mathbf{m G 3 A}$ and $\mathbf{\text { MG}} \mathbf{A}$, Fig. S28, ESI $\dagger)$ and another Lewis acid $\left(\mathrm{BF}_{3} \mathrm{O}(\mathrm{Et})_{2} \text {, Fig. S29, } \mathrm{ESI}^{1}\right)^{18}$ also showed the absolutely same behaviour that supports the stepwise complexation from the outer layer. These results are opposite compared to those obtained for PG4A and clearly indicate that the potential gradient in the dendritic structure is inverted by changing the binding position of the phenylazomethines from the para to meta position.

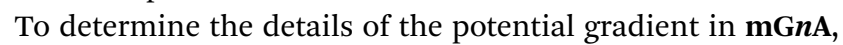
titration with a weak acid $\left(\mathrm{H}^{+}\right.$, trifluoroacetic acid) was performed according to the literature method that was used to determine the

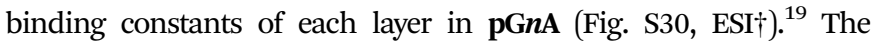
results clearly show that the outer layer has a higher binding constant for $\mathrm{H}^{+}$and it sequentially decreases toward the inner layer in all generations of $\mathbf{~} \mathbf{G} \boldsymbol{n A}$, but the slope is steeper in $\mathbf{~} \mathbf{G} \boldsymbol{n} \mathbf{A}$ because, probably, the resonance donation is stronger than inductive withdrawal (Fig. S31, ESI $\dagger$ ).

To understand the potential gradient of DPAs, the features of the meta and para substituted phenylazomethines have to be 
understood. Ether and amino substituents are known to have a significant difference in the para and meta substituent effects (in some cases, the donating group changes to a withdrawing group $)^{20}$ which is explained by the effectivity of the resonant donation from the lone-pair. To determine the substituent effect of the phenylazomethines, the redox potentials of the phenylazomethine linked ferrocenes (Fig. 1) were measured (Fig. S32, $\mathrm{ESI}+$ ). The redox potentials $\left(\mathrm{V} v s . \mathrm{Fc} / \mathrm{Fc}^{+}\right.$) of $\mathbf{p F c}$ and $\mathbf{m F c}$ were $-10 \mathrm{mV}$ and $+15 \mathrm{mV}$, respectively. This clearly indicates that para substitution of the phenylazomethine is electron donating, while meta-substitution is electron withdrawing.

For further investigation of the expression mechanism of the potential gradient in DPAs, the ${ }^{13} \mathrm{C}$ and ${ }^{15} \mathrm{~N}$ NMR spectra were studied (Fig. 4 and Fig. S33-S35, ESI $\dagger$ ). The NMR spectra of the azomethines are complicated and the assignment was difficult because the cis and trans positions of the $\mathrm{C}=\mathrm{N}$ bond are nonequivalent. Therefore, the spectra of each compound were compared to those of the outer-layer ${ }^{13} \mathrm{C}=\mathrm{N}$ labelled DPAs and inner-layer $\mathrm{C}={ }^{15} \mathrm{~N}$ labelled DPAs (prepared by using ${ }^{13} \mathrm{C}$ labelled benzophenone $\left({ }^{13} \mathrm{C}=\mathrm{O}\right)$ and ${ }^{15} \mathrm{~N}$ labelled aniline) for the assignment of the outerlayer ${ }^{13} \mathrm{C}$ NMR spectra and the inner-layer ${ }^{15} \mathrm{~N}$ NMR spectra. The ${ }^{13} \mathrm{C}$ NMR spectra of the outermost $\mathrm{C}=\mathrm{N}$ carbons showed the highest chemical shift in both mGnA and pGnA (Fig. S33, ESI $\dagger$ ). This indicates that the outermost $\mathrm{C}=\mathrm{N}$ carbon is de-shielded compared to the other layer carbons. Assignments of other layers are difficult, but it is assumed that the environment around the $\mathrm{C}=\mathrm{N}$ carbons (NOE from ${ }^{1} \mathrm{H}$ atom) is similar, therefore, the integration is helpful information. The integration value of MG4A is $8,6(4+2), 1$ from the low field to the high field, and the peak with a value of 6 has a small peak value in the higher field. This means that the ${ }^{13} \mathrm{C}=\mathrm{N}$ chemical shift is sequentially shifting from the outer layer to the inner layer.

(a)

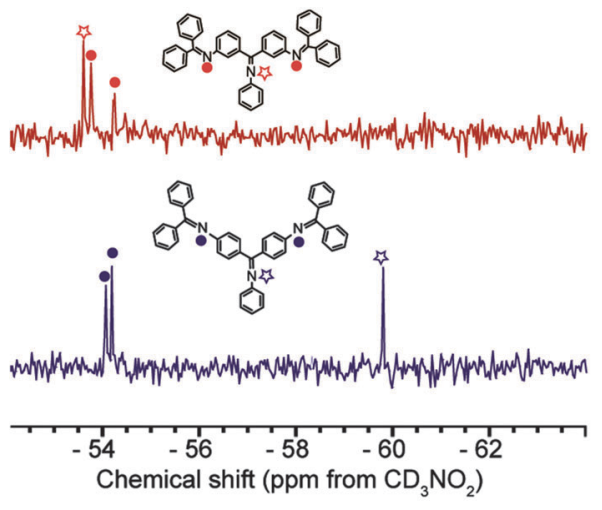

(b)

Resonance T-polarization
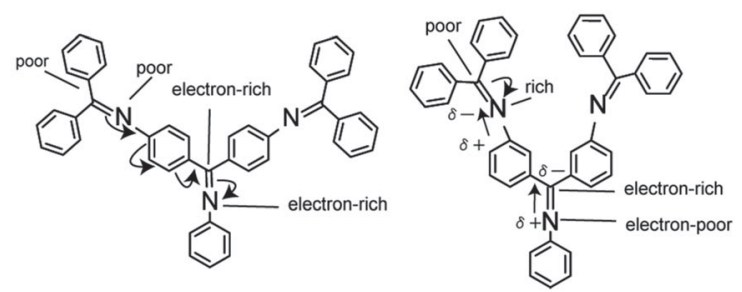

Fig. 4 (a) ${ }^{15} \mathrm{~N}$ NMR spectra of $\mathbf{m G} 2 \mathrm{~A}$ and $\mathbf{p G} 2 \mathrm{~A}$ in $\mathrm{CDCl}_{3}$. (b) The proposed expression mechanism of the electron density gradient of the nitrogen atom.
On the other hand, the ${ }^{15} \mathrm{~N}$ NMR spectra of mG2A showed that the outer layer $\mathrm{C}=\mathrm{N}$ nitrogen is more shielded than the inner layer nitrogens, and in the case of pG2A, it showed the opposite trend (Fig. 4(a)). The complexation of acids with the imine reflects the electron density of the nitrogen atom, and the outer layer shielding (= higher electron density) of mG2A agrees with the stepwise complexation from the outer layer. The inner layer shielding (= higher electron density) behaviour of pG2A also agrees with the stepwise complexation from the inner layer. The difference in the chemical shift between the first and second layers is smaller in mG2A compared to pG2A which also agrees with the complexation constants that are determined by the titration with TFA. However, even the ${ }^{15} \mathrm{~N}$ NMR spectra match the complexation behaviour, the ${ }^{13} \mathrm{C}$ NMR spectra of $\mathbf{m G n A}$ show the opposite electron density compared to that shown in the ${ }^{15} \mathrm{~N}$ NMR spectra (inner layer shielded). This can be explained by the mechanism of the electron donation or withdrawal (Fig. 4(b)). In pGnA, the electron donation from the outer layer is a resonance mechanism and the inner-layer carbon and nitrogen are both shielded, but in $\mathbf{m G n A}$, the electron withdrawal is a $\pi$-polarization mechanism ${ }^{21}$ in which the $\mathrm{C}=\mathrm{N}$ bond takes $\mathrm{a}^{\delta-} \mathrm{C}=\mathrm{N}^{\delta+}$ type polarized electronic structure (Fig. $4 \mathrm{~b}$ ).

In conclusion, a new meta-substituted phenylazomethine dendrimer was synthesized. This dendrimer showed a stepwise radial complexation from the outer layer to the inner layer which was opposite compared to that shown by the para-substituted phenylazomethine dendrimers. The inversion of the potential gradient could be explained by the substituent effect of the repeat unit. Of course, this dendrimer can expand the range of DPA applications. For example, the greater variation in the accumulable numbers and combinations of metal atoms (Fig. S36, $\mathrm{ESI} \dagger$ ) has an important meaning. However, the inversion of the potential gradient and the discovery of a simple mechanism have a more significant fundamental meaning. It is a novel method to design and control the intramolecular potential structure.

K. A. thanks Dr Kensaku Takanashi for useful discussions. This work was supported in part by the CREST program of the Japan Science and Technology (JST) Agency, a Grant-in-Aid for Scientific Research on Innovative Areas "Molecular Architectonics: Orchestration of Single Molecules for Novel Functions", and by JSPS KAKENHI Grant No. 26410128, 24350116, and 21108009.

\section{Notes and references}

1 D. A. Walker, Trends Plant Sci., 2002, 7, 183.

2 A. K. Viswanath, in Handbook of Advanced Electronic and Photonic Materials and Devices, ed. H. S. Nalwa, Academic Press, San Diego, 2001, ch. 3, vol. 1, pp. 109-188.

3 (a) C. W. Tang and S. A. VanSlyke, Appl. Phys. Lett., 1987, 51, 913; (b) B. Geffroy, P. le Roy and C. Prat, Polym. Int., 2006, 55, 572; (c) O. Nuyken, S. Jungermann, V. Wiederhirn, E. Bacher and K. Meerholz, Monatsh. Chem., 2006, 137, 811; (d) S. Lo and P. L. Burn, Chem. Rev., 2007, 107, 1097.

4 (a) C. W. Tang, S. A. VanSlyke and C. H. Chen, J. Appl. Phys., 1989, 65, 3610; (b) T. M. Clarke and J. R. Durrant, Chem. Rev., 2010, 110, 6736; (c) P. V. Kamat, K. Tvrdy, D. R. Baker and J. G. Radich, Chem. Rev., 2010, 110, 6664; (d) A. L. Fahrenbruch and R. H. Bube, Fundamentals of solar cells, Academic Press, London, 1983.

5 (a) D. Astruc, E. Boisselier and C. Ornelas, Chem. Rev., 2010, 110, 1857; (b) M. Fischer and F. Vögtle, Angew. Chem., Int. Ed., 
1999, 38, 884; (c) A. W. Bosman, H. M. Janssen and E. W. Meijer, Chem. Rev., 1999, 99, 1665; (d) G. R. Newkome and C. Shreiner, Chem. Rev., 2010, 110, 6338; (e) S. M. Grayson and J. M. J. Fréchet, Chem. Rev., 2001, 101, 3819.

6 (a) S. Campagna, S. Serroni, F. Puntoriero, C. Di Pietro and V. Ricevuto, in Electron Transfer in Chemistry, ed. V. Balzani, WileyVCH, Weinheim, 2001, vol. 5; (b) A. Adronov, S. L. Gilat, J. M. J. Fréchet, K. Ohta, F. V. R. Neuwahl and G. R. Fleming, J. Am. Chem. Soc., 2000, 122, 1175; (c) A. Bar-Haim, J. Klafter and R. Kopelman, J. Am. Chem. Soc., 1997, 119, 6197; (d) V. Balzani, P. Ceroni, M. Maestri and V. Vicinelli, Curr. Opin. Chem. Biol., 2003, 7, 657; (e) U. Hahn, M. Gorka, F. Vögtle, V. Vicinelli, P. Ceroni, M. Maestri and V. Balzani, Angew. Chem., Int. Ed., 2002, 41, 3595; $(f)$ K. Albrecht, Y. Kasai and K. Yamamoto, J. Inorg. Organomet. Polym. Mater., 2009, 19, 118; $(g)$ M.-S. Choi, T. Aida, H. Luo, Y. Araki and O. Ito, Angew. Chem., Int. Ed., 2003, 42, 4060.

7 (a) Z. Xu and J. S. Moore, Acta Polym., 1994, 45, 83; (b) T. Tada, D. Nozaki, M. Kondo and K. Yoshizawa, J. Phys. Chem. B, 2003, 107, 14204; (c) J. Wang, J. Yan, Z. Tang, Q. Xiao, Y. Ma and J. Pei, J. Am. Chem. Soc., 2008, 130, 9952; (d) C. Chotsuwan and S. C. Blackstock, J. Am. Chem. Soc., 2008, 130, 12556; (e) T. D. Selby and S. C. Blackstock, J. Am. Chem. Soc., 1998, 120, 12155; $(f)$ K. Bronk and S. Thayumanavan, J. Org. Chem., 2003, 68, 5559; $(g)$ M. Holzapfel and C. Lambert, J. Phys. Chem. C, 2008, 112, 1227; (h) C. Lambert, J. Schelter, T. Fiebig, D. Mank and A. Trifonov, J. Am. Chem. Soc., 2005, 127, 10600; (i) A. Nantalaksakul, A. Mueller, A. Klaikherd, C. J. Bardeen and S. Thayumanavan, J. Am. Chem. Soc., 2009, 131, 2727.

8 (a) K. Yamamoto, M. Higuchi, S. Shiki, M. Tsuruta and H. Chiba, Nature, 2002, 415, 509; (b) K. Yamamoto and K. Takanashi, Polymer, 2008, 49, 4033.

9 (a) K. Albrecht and K. Yamamoto, J. Am. Chem. Soc., 2009, 131, 2244; (b) M. Kathiresan and L. Walder, Macromolecules, 2011, 44, 8563.

10 (a) K. Yamamoto, T. Imaoka, W. J. Chun, O. Enoki, H. Katoh, M. Takenaga and A. Sonoi, Nat. Chem., 2009, 1, 397; (b) N. Satoh, T. Nakashima, K. Kamikura and K. Yamamoto, Nat. Nanotechnol.,
2008, 3, 106; (c) T. Imaoka, H. Kitazawa, W. J. Chun, S. Omura, K. Albrecht and K. Yamamoto, J. Am. Chem. Soc., 2013, 135, 13089.

11 (a) T. Imaoka, N. Inoue and K. Yamamoto, Chem. Commun., 2012, 48, 7235; (b) T. Imaoka, H. Ueda and K. Yamamoto, J. Am. Chem. Soc., 2012, 134, 8412.

12 (a) D. A. Tomalia, J. Nanopart. Res., 2009, 11, 1251; (b) D. A. Tomalia, Soft Matter, 2010, 6, 456.

13 (a) T. Imaoka, R. Tanaka, S. Arimoto, M. Sakai, M. Fujii and K. Yamamoto, J. Am. Chem. Soc., 2005, 127, 13896; (b) T. Imaoka, R. Tanaka and K. Yamamoto, Chem. - Eur. J., 2006, 12, 7328.

14 M. Higuchi, M. Tsuruta, H. Chiba, S. Shiki and K. Yamamoto, J. Am. Chem. Soc., 2003, 125, 9988.

15 K. Takanashi, H. Chiba, M. Higuchi and K. Yamamoto, Org. Lett., 2004, 6, 1709.

16 (a) V. J. Weinmayr, J. Am. Chem. Soc., 1955, 77, 3012; (b) H. Ping, K. Zhao and H. Xu, Molecules, 2001, 6, M250.

17 Optimized with semi-empirical calculation with AM1 hamiltonian on Gaussian 09, Revision C.01 on the nodes of a supercomputer (TSUBAME2, Tokyo Institute of Technology). Gaussian 09, Revision C.01, M. J. Frisch, et al. (full list is in ESI $\dagger$ ).

18 K. Takanashi, A. Fujii, R. Nakajima, H. Chiba, M. Higuchi, Y. Einaga and K. Yamamoto, Bull. Chem. Soc. Jpn., 2007, 80, 1563.

19 K. Yamamoto, M. Higuchi, A. Kimoto, T. Imaoka and K. Masachika, Bull. Chem. Soc. Jpn., 2005, 78, 349.

20 C. Hansch, A. Leo and R. W. Taft, Chem. Rev., 1991, 91, 165.

21 (a) D. J. Craik and R. T. C. Brownlee, Prog. Phys. Org. Chem., 1983, 14, 1; (b) W. F. Reynolds, Prog. Phys. Org. Chem., 1983, 14, 165; (c) G. K. Hamer, J. R. Peat and W. F. Reynolds, Can. J. Chem., 1973, 51, 897; (d) J. Bromilow, R. T. C. Brownlee, D. J. Craik, P. R. Fiske, J. E. Rowe and M. Sadek, J. Chem. Soc., Perkin Trans. 2, 1981, 753; (e) K. Neuvonen, F. Fulop, H. Neuvonen, A. Koch, E. Kleinpeter and K. Pihlaja, J. Org. Chem., 2001, 66, 4132; $(f)$ K. Neuvonen, F. Fulop, H. Neuvonen, A. Koch, E. Kleinpeter and K. Pihlaja, J. Org. Chem., 2003, 68, 2151; $(g)$ G. F. Fadhil, H. A. Radhy, A. Perjessy, M. Samalikova, E. Kolehmainen, W. M. F. Fabian, K. Laihia and Z. Sustekova, Molecules, 2002, 7, 833. 